Nordic Concrete Research - Publ. No. NCR 61 - ISSUE 2 / 2019 - Article 3, pp. 39-51

\begin{tabular}{|l|r|}
\hline \multicolumn{1}{|c|}{ S sciendo } & \begin{tabular}{c} 
NCF $\begin{array}{l}\text { Nordic } \\
\text { Concrete } \\
\text { Federation }\end{array}$ \\
\hline $\begin{array}{l}\text { (C) Article authors. This is an open access article distributed under } \\
\text { the Creative Commons Attribution-NonCommercial-NoDerivs } \\
\text { licens. (http://creaticecommons.org/licenses/by.nc-nd/3.0/). }\end{array}$
\end{tabular} \\
\hline & $\begin{array}{r}\text { ISSN online 2545-2819 } \\
\text { ISSN print } \quad 0800-6377\end{array}$ \\
DOI: $10.2478 /$ ncr-2019-0016 & $\begin{array}{r}\text { Received: Sept. 6, 2019 } \\
\text { Revision received: Nov. 25, 2019 }\end{array}$ \\
& Accepted: Nov. 26, 2019 \\
\hline
\end{tabular}

\title{
The Choice of Materials for the E39 Fjord Crossing Project
}

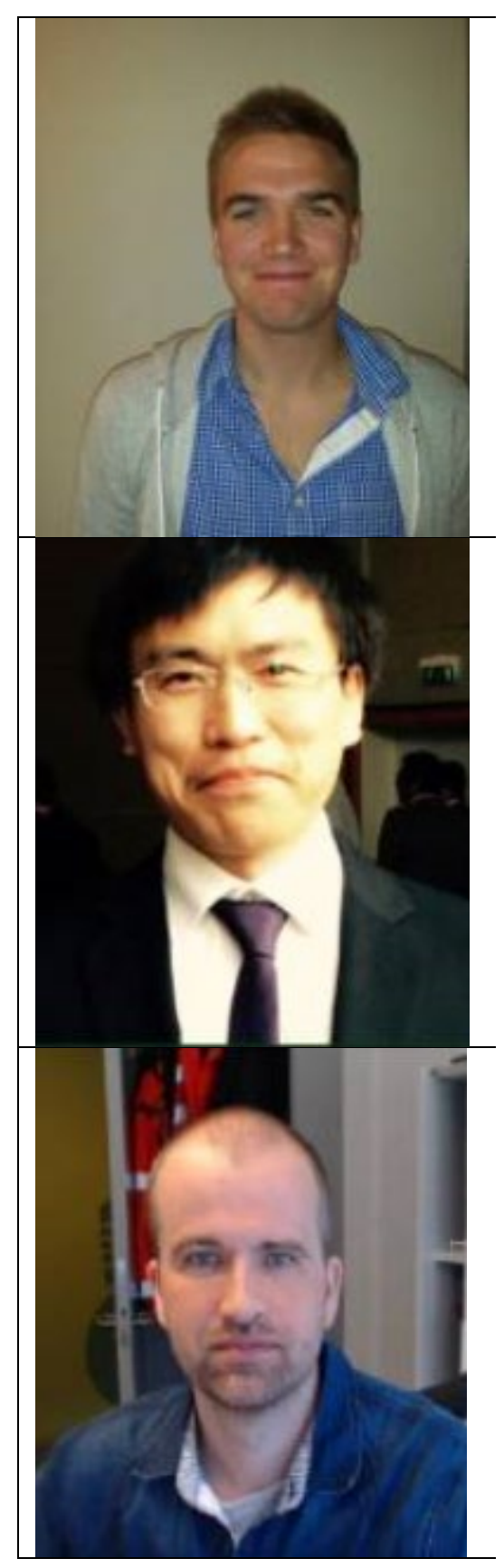

Simen Hellgren Holtberget

Engineer for Norwegian Public Road Administration

Østensjøveien 34, Oslo

simen.hellgren.holtberget@vegvesen.no

Xu Xiang

Senior Engineer for Norwegian Public Road Administration Brynsengfaret 6A, Oslo

xu.xiang@vegvesen.no

Cato Dørum

Chief Engineer for Norwegian Public Road Administration

Parkgata 81, Hamar

cato.dorum@vegvesen.no 


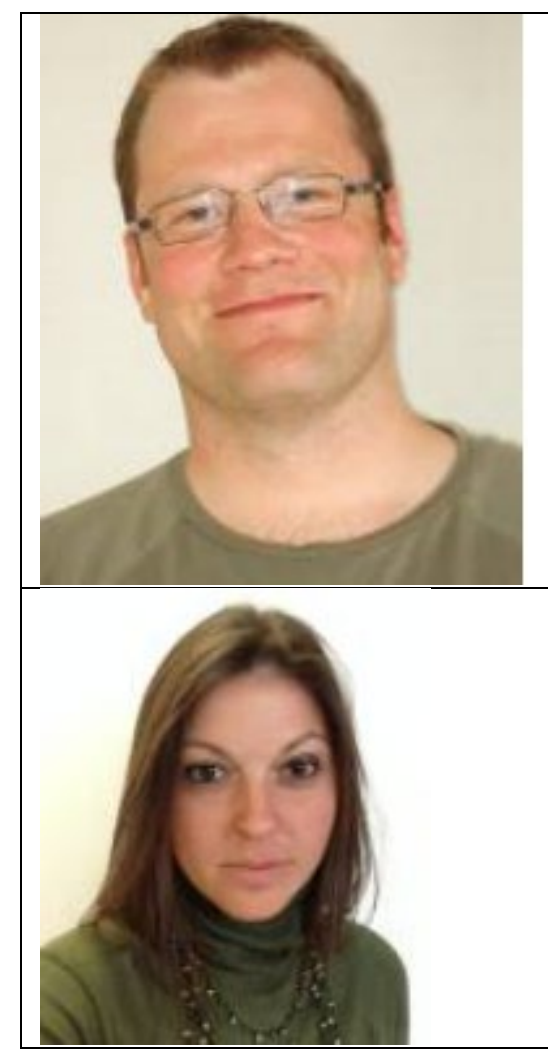

Johannes Veie

Chief Engineer for Norwegian Public Road Administration

Parkgata 81, Hamar

johannes.veie@vegvesen.no

Arianna Minoretti

Chief Engineer for Norwegian Public Road Administration

Abels Gate 5, Trondheim

arianna.minoretti@vegvesen.no

\begin{abstract}
In the studies for crossing the long and deep Norwegian fjords along the E39 road, on the west coast of Norway, some challenging structures have been evaluated. Some of them are known structures, like floating bridges, and some others are structures never built before, like suspension bridges on tension leg platforms and submerged floating tube bridges. In the development of the feasibility studies for these crossings, the choice of materials has played an important role. The materials influence not only the design and the cost, but also the behaviour of the structure towards the environmental loads and some particular loads as the ship collision. The article illustrates the different solutions proposed for the fjord crossings and discusses the influence in the choice of the material, with special regards to the type of concrete. The pros and cons of the application of the light weight concrete are discussed.
\end{abstract}

Key words: Materials, concrete, light weight concrete, bridges.

\title{
1. INTRODUCTION
}

\subsection{The E39 fjord crossing project}

The Norwegian National Transport Plan of 2013 was the first that included the crossings along the E39. The need for an improvement in the transport system along the west coast of Norway has driven the political choices since then. The west coast produces more than $50 \%$ of the national export but the presence of the 7 ferries that interrupt the European road, implying 21 hours for driving it, is a huge boundary for the development of an important economical area. Apart from 
the oil\&gas field, the Norwegian coast is home of the aquaculture activities, that are developing fast representing a huge possibility also for the future of the country. Aside from this, the need of avoiding the depopulation of the rural areas, coveted by the politicians, can be guaranteed just providing services to the delocalized population: hospitals, schools and jobs must be easy and fast to reach, and a road that can be travelled in half time is a key issue for the strategic plans for the future of a country.

The possibility to bring the need of a ferry free E39 into reality depends on the chance to have feasible technological solutions to cross the long and deep fjords along the road.

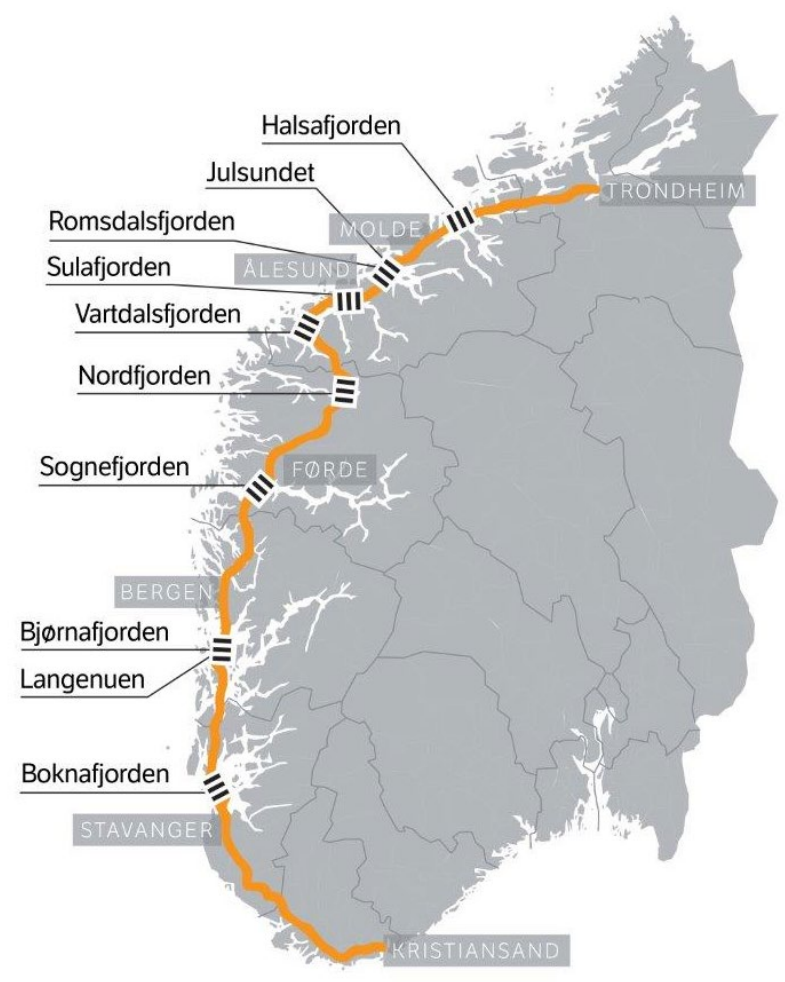

Figure 1 - Crossings along the E39, Statens vegvesen

Some of the fjords are too wide and deep to rely on traditional bridges solutions. In 2011 a study has been done for the Sognefjord, the deepest fjord along the road, to evaluate which solutions the further studies should focus on. The Sognefjord would be a crossing of around 4 kilometres in an area where the sea depth can reach 1.3 kilometres. The solutions proposed for the Sognefjord, like suspension bridges on tension leg platforms, floating bridges and submerged floating tube bridges, could be investigated also for the other fjords.

Challenging feasibility studies have started since 2014 and different solutions for crossing these fjords have been evaluated in detailed feasibility studies, comparing the different alternatives and considering the most recent results of the scientific research to optimize the design of these structures.

Within the E39 fjord crossing project, more than $50 \mathrm{PhD}$ 's have been financed to develop research studies directly connected to the project. Nevertheless, the design choices are also based on proven industry practice, considering that new technologies have to be proven in practice, either as part of a project or as a pilot.

\section{2}

\section{The challenges for the Norwegian fjords}

The bridges proposed for the Norwegian crossings along the E39 are exposed to some specific challenges related to the fjord area. Some fjords are very aggressively exposed to environmental loads, while others may be interested to the passage of larger ships or to more challenging geotechnical conditions. This affects which structure is most suited to each fjord.

The intensity of the environmental loads can vary, depending on the exposure of the specific crossing. Wind, current and waves are affecting the design of the different bridges, but while the 'oversea bridges' don't have any way to shield the environmental loads, the submerged floating 
tube bridge (SFTB) can naturally reduce the loads it is exposed to with the submergence. The SFTB proposed for the Bjørnafjord crossing was able, with just 30 meters of submergence, to provide a zero-downtime crossing, even with the worst environmental condition in the next 100 years.

On the other side, loads like fires and explosions have a different impact in open structures and implies challenging requirements for a closed-section structure, due to the effect of the confinement.

Collisions with submarines have been considered for the different structures, considering the submerged part of the bridges. This particular load could affect subsea anchorages, causing the loss of a tether, or, in the case of the SFTB, a collision could occur between the submarine and the submerged bridge and this situation must be considered in the load set for the design.

Collisions with ships have also to be included in the design for the Norwegian fjords, because the fjords are a huge attraction for the tourism system and even large cruise ships could enter some of the fjords. The SFTB vertically stabilised with tethers connecting the structure with the seabed is the only one, among the proposed structures, that can avoid the risk of collision with ships with a submergence of approximatively 20 meters. The solution with floating pontoons is, instead, exposed to the ship collision risk. A particular connection between the pontoons and the submerged bridge has been developed, in order to interrupt the transmission of the loads in case of a collision with a big ship. Obviously, the pontoons must be replaceable and the structure must survive a collision with a big ship with full traffic on the bridge. For the floating bridge and the multi-span suspension bridge on floating foundations, there is no possibility to avoid the risk of a ship collision, even if the risk for the two structures is very different. For the floating bridge, having several possible collision points, the design of the structure and the choice of materials have been strongly influenced by this challenging load.

\subsection{Ship collision}

During a collision event the instantaneously weaker body deforms. A typical collision between two bodies of similar strength may start with the ship bow penetrating slightly into the bridge structure, until enough membrane forces are mobilized in the bridge structure side structure to start crushing the incoming vessel bow. The deformation of the bodies is normally very sensitive to changes in the relative strength, and small changes in the resistance to deformation of one of the bodies can change the interaction regime completely.

In NORSOK N-004 (NORSOK N-004, Design of steel structures. Rev. 2, Oct., 2004.), analysis or design against ship collision is categorized into three regimes that depend on the relative strength, illustrated in the figure below. For many structures, and in particular concrete structures, it is advisable to focus on the strength design approach; in which the strength of the concrete structure must be sufficient to initiate crushing of the striking ship bow. Once the bow starts to crush, the main kinetic energy will be dissipated through bow deformation and not through deformation of the bridge, thereby limiting the local collision damage. Repairable steel structures may be designed to allow for more local damage (and act similarly to a bumper beam; dissipating impact energy while protecting the main structural elements) if it is beneficial for the bridge integrity. For the floating bridge concept, a relatively soft structural design of the steel pontoons limits the forces that are transmitted to the bridge column, bridge girder and abutments during a ship impact event. 
A pure strength design with no damage to the bridge is normally not feasible, and some damage must be expected. However, the damage should be limited and easily repairable. From an accidental limit state (ALS) perspective, large damage can be allowed provided that the structural integrity and damage stability of the bridge is maintained.

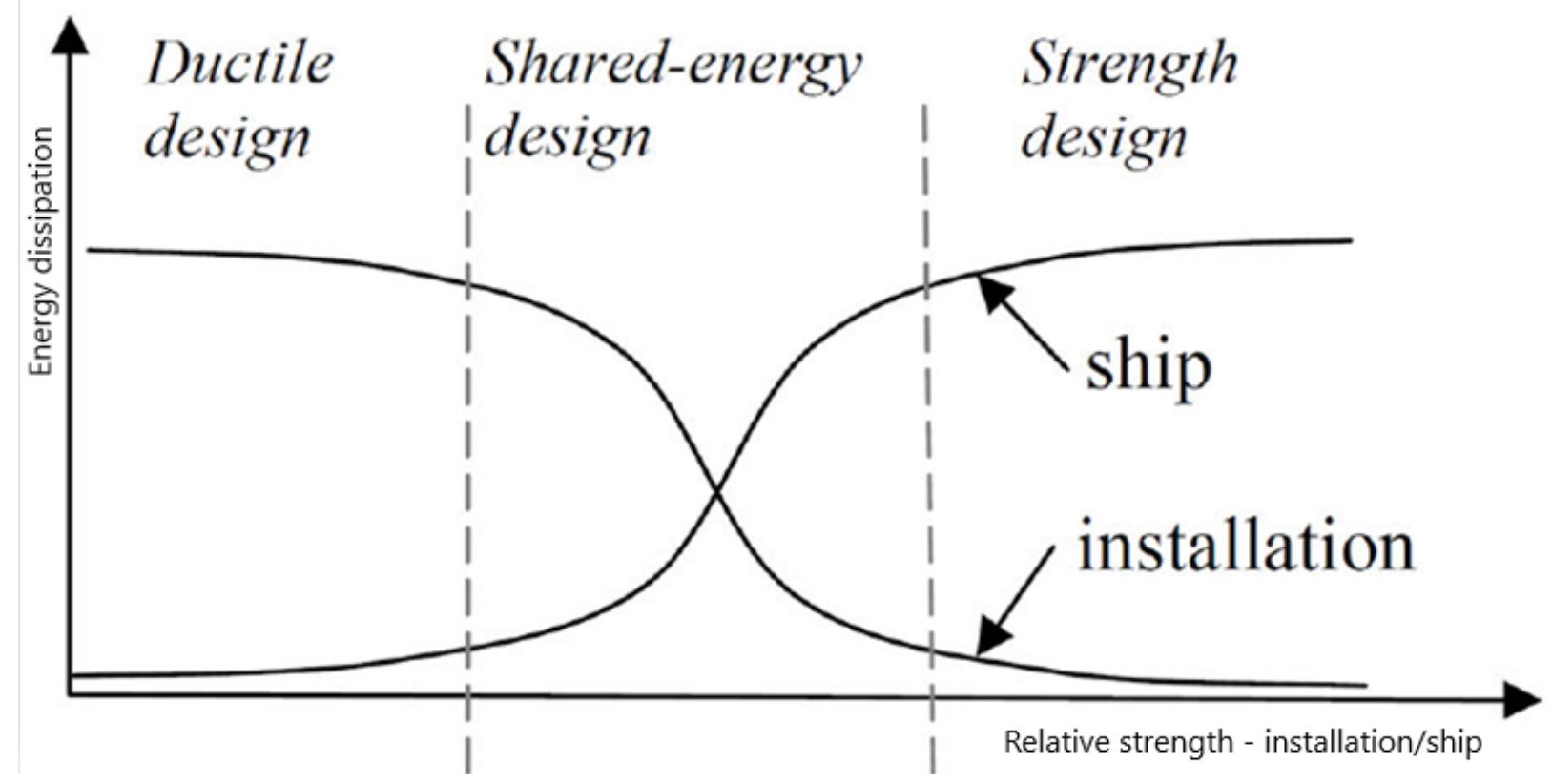

Figure 2 - Characterization of design principles in terms of relative strength.

\section{$1.4 \quad$ Research question: the choice of materials}

The choice of the materials for the different bridges and for each part of their structure has been strongly influenced, at the beginning of the studies, by the experience gathered with the design of bridges and offshore structures in the Norwegian environment.

Concrete has played a key role in the design of durable structures and the availability of data from monitoring test in the real environment has given a reliable base for the choice of the parameters in the design. This is for example the case of the 'Statpipe shore approach', a SFTB-type of structure built in 1980 in Kårstø to guide and protect two gas pipelines. The structure was realized with two rectangular concrete tubes to allocate the pipelines and the most recent knowledge on the design for the offshore concrete was applied, to provide a durable structure in an aggressive environment. The material of the structure was monitored for 26 years and the results strongly contribute to the actual knowledge of the concrete behaviour in marine environment.

Nevertheless, the cost evaluation, combined with some specific need for the behaviour towards the environmental loads, has sometimes made to lean towards steel as a preferred material. This was, for example, the case for the design of the floating bridge on the Bjørnafjord.

For the SFTB, the large European experience with concrete in the subsea structures, brought the choice towards concrete. In addition, the structure needs to be ballasted, to balance the large uplifting force, and the possibility to have a structural material that also acts as a ballast, was seen as the preferred solution. 
The need of limit the mass of the structures has brought to the evaluation of the lightweight aggregate concrete (LWAC) as a possible alternative. Further considerations regarding the properties of the material, compared with the challenges related to the application to the Norwegian fjords area, have been discussed during the design. Finally, the possibility of tuning the behaviour of the structure, with the change of the material used, has shown a unexpected possibility that could solve some main issues during the design.

\subsection{Research method}

All these steps have been done, at first, with a simplified procedure combining modal analysis, basic structural design and industry standards [1] and, after that, with more advanced tools. These are tools used for the bridge design and other normally used for the offshore field, that have never been applied to bridge-structures. The doubts for this application were relaed to the fact that offshore structures are more punctual and more rigid structures, respect to a slender bridge, and that the bridges analysed are exposed to lower sea-state respect to the offshore platforms. This could affect the analyses in terms of accuracy of the results. For this reason, a complex system has been implemented to demonstrate the reliability of the results. It implies code-code verifications, the comparison with simplified method and the comparison with the results from the test. The work done for the studies related to the E39 has demonstrated the feasibility of the method and of the tools used but a further effort in the testing part is necessary for the detailed design of these structures.

The considerations done in the following summarize the results achieved during the feasibility studies developed for these structures, as a case study applied to the fjord crossing in Norway.

2. THE SUSPENSION BRIDGE ON TENSION LEG PLATFORMS

2.1 The structure

The multi-span suspension bridge on floating foundations (MSBFF) is a structure which combines the technology of modern suspension bridge design with state-of-the-art technology from the offshore oil and gas industry. The bridge consists of a multi-span suspension bridge where one or more of the towers are founded on a floating tension legged platform (TLP), anchored to the seafloor. The TLP technology gives a good foundation for a multi-span suspension bridge, since the technology gives rotational (about the horizontal axes), vertical and lateral stiffness to the structure. Even though there is stiffness, the structure is still flexible enough to prevent restraining forces from e.g. temperature, ship collision and traffic. In principle the TLP works as a reversed pendulum, which makes it ideal as a support for a multi-span suspension bridge. 


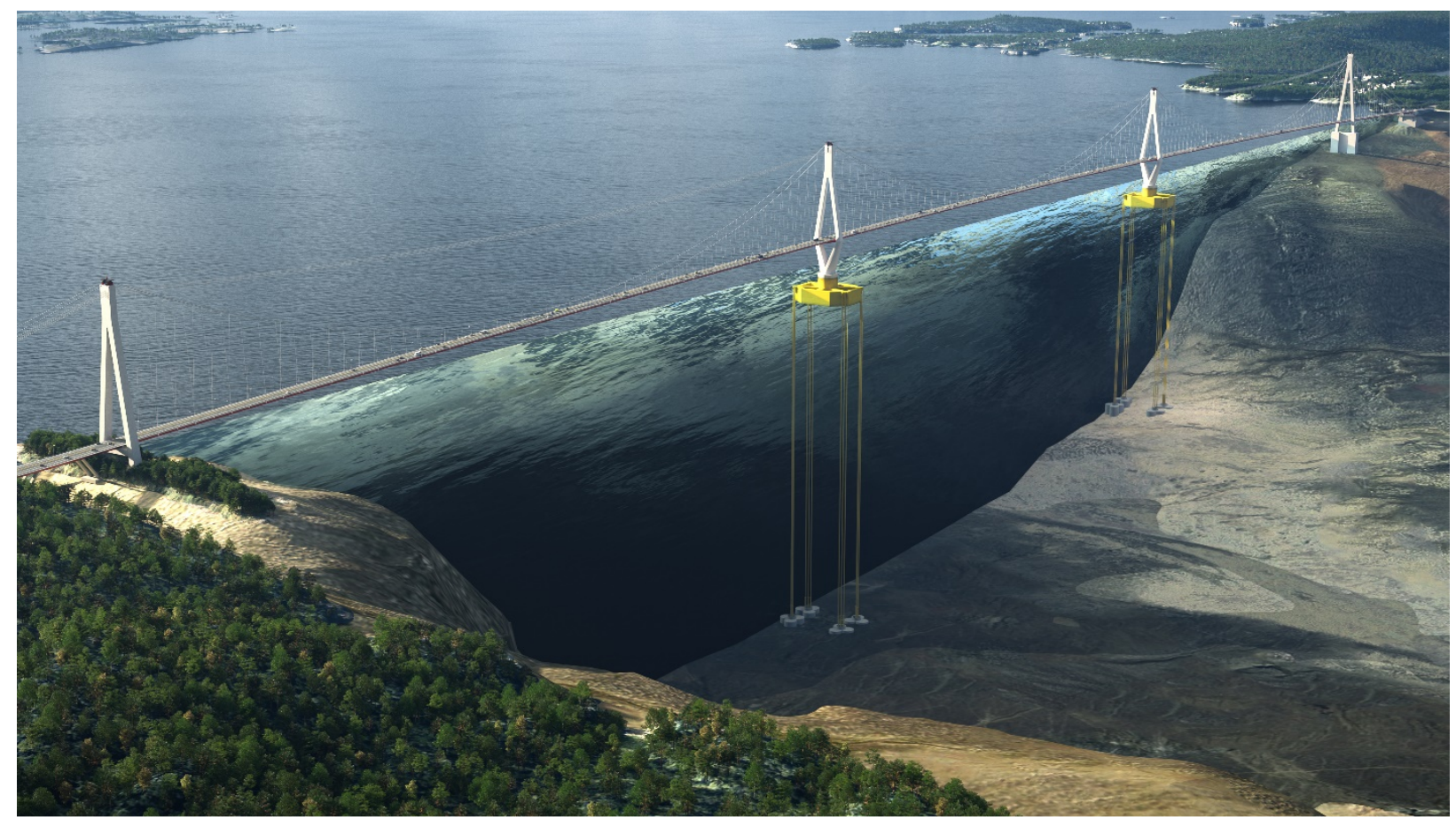

Figure 3 - Illustration of the MSBF, Statens vegvesen

The concept is suitable for different crossings of deep water from $2 \mathrm{~km}$ and upwards. So far, the concept has been suggested for the crossing of Boknafjorden, Bjørnafjorden, Halsafjorden and Sulafjorden. Especially for Bjørnafjorden the concept development has been performed in detail, including construction and installation.

\subsection{Influence of the materials}

Dependent on the site of the bridge, and the desired performance of the floaters, different materials may be used. Throughout the concept development, steel, concrete and lightweight aggregate concrete (LWAC) have been looked at as alternatives. The tether tension and the connection to the lateral stiffness of the structure makes LWAC an advantageous material. The tuning of the dynamic behaviour of the structure can be done by looking at different material types, and LWAC is advantageous with this in mind.

In order to get the required stiffness from the floater the buoyancy needs to be large enough, but increasing the size if the floater also gives an increase of the wave and current load effect on the structure. In order to get the ideal combination of stiffness and load effect, LWAC concrete has been used in combination with normal concrete in the floaters. The combination also lets the designers adjust the metacentre of the floater, which is especially advantageous for the construction and installation phase. With this in mind, the floaters can be designed with a bottom slab in normal concrete, and the rest with LWAC.

A typical floater design is presented below with weight and buoyancy: 
Nordic Concrete Research - Publ. No. NCR 61 - ISSUE 2 / 2019 - Article 3, pp. 39-51

Table 1 - Buoyancy of the concrete floater

\begin{tabular}{lc}
\hline \multicolumn{1}{c}{ Component } & Weight \\
[MN] & 680 \\
Concrete & 345 \\
Bridge and pylon & 15 \\
Mechanical outfitting + anodes & 180 \\
Ballast water & 360 \\
Tether tension & $\mathbf{1 5 8 0}$ \\
SUM & \\
\hline
\end{tabular}

This design gives a draft of $47 \mathrm{~m}$. The configuration consists of approx. $31000 \mathrm{~m}^{3}$ of concrete where $4700 \mathrm{~m}^{3}$ is normal concrete, and the rest is LWAC. In comparison the Heidrun TLP platform consists of about $35000 \mathrm{~m}^{3}$ of concrete.

\subsection{The choice for the E39}

The choice of materials for the floaters is highly dependent on the depth, and environmental conditions on the specific site. This means that different material alternatives may be suitable at

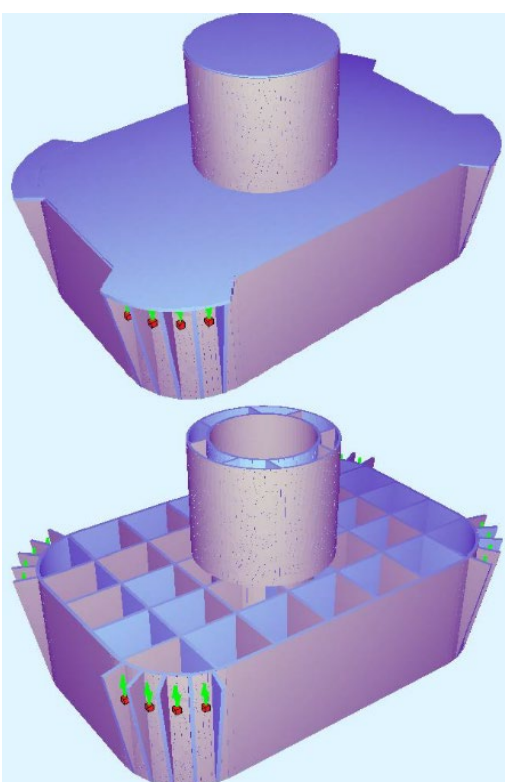

Figure 4 - Typical concrete floater, $S V V$ different fjord crossings. With regard to performance the concrete and steel alternatives are considered fairly equal. However, there is differences when you look at the construction and installation phase, and the maintenance and operation of the bridge. The concept is designed for a minimum of 100-year design working life, and regarding durability the difference between the materials is more pressing. Both materials have been concluded to be suitable for the 100-year working life, but the difference in required maintenance may affect the choice of material. An attractive alternative here is the potential use of high performance concrete in combination with normal concrete to increase durability. Ship collision is another matter where the difference between the materials can be decisive. The possibility of retrofit design is another one, and the materials characteristics with regard to repair and changes may be important. But in total both steel and concrete are considered suitable for the floaters.

\subsection{Further applications}

The further application of material for the E39 project depends heavily on the specific site requirements, and the wanted performance of the structure. Another important aspect is the focus 
on climate challenges and the requirement of more environmentally friendly materials. This especially affects the use of high strength concrete, and the availability of this in the future. The technological development of both steel and concrete production, construction and characteristics, and the knowledge and experience in the industry, is very important for the further choice of materials for the E39 project. This development of common practice in the industry may be crucial for the feasibility of further projects.

THE SUBMERGED FLOATING TUBE BRIDGE

\section{1}

\section{The structure}

The Submerged Floating Tube Bridge (SFTB) is a floating tube bridge, submerged at a defined position under the sea level.

For short crossings, the structure could have one single span between the shores and for shallow waters, intermediate supports could be provided for the structure. On the contrary, for the applications on the Norwegian fjords, solutions suitable for deep and wide crossings must be applied. The SFTBs proposed for the E39 are vertically stabilized by floating pontoons or tethers, connecting the structure with the seabed.

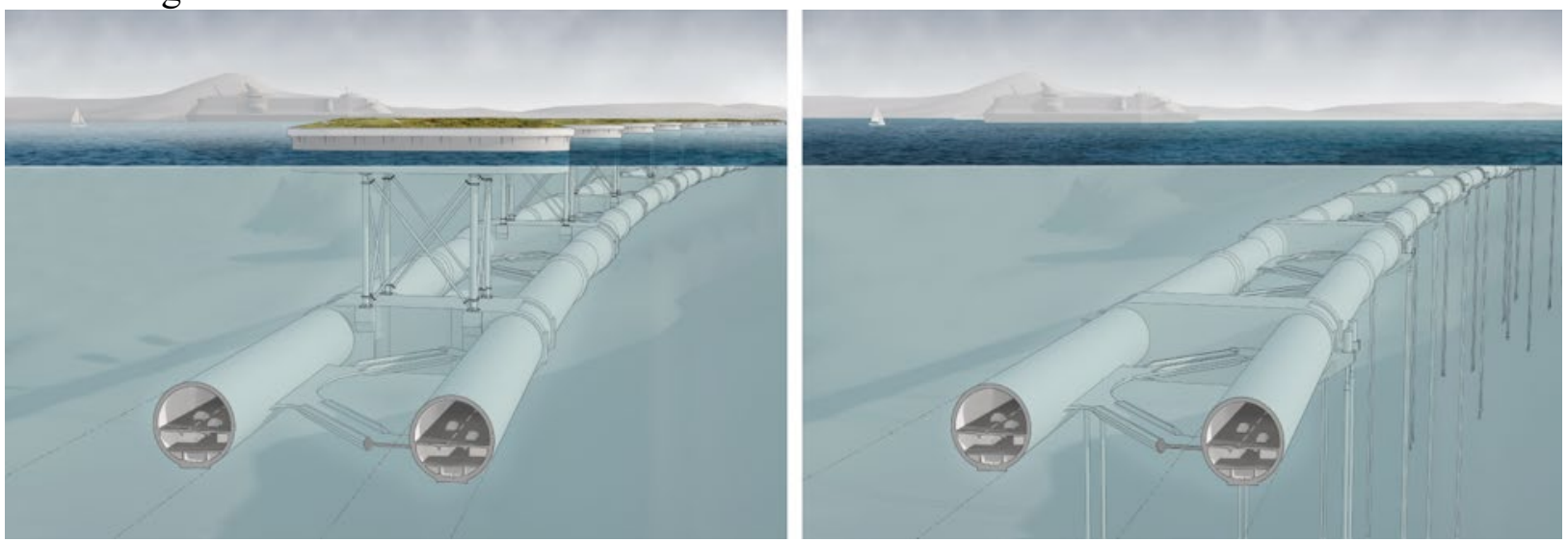

Figure 5 - SFTB with pontoons or tethers, Statens vegvesen

The bridge is neutrally buoyant, balancing the Archimedes' lifting force with the ballast located into the structure. The solution with tethers has a positive buoyancy located into the crossing braces connecting the twin tubes, due to the tension requirement for the tether system.

The bridge is a twin tube bridge for every study developed for the crossings along the E39. The reasons for this choice are several. First of all, a twin tube is a stable cross section towards the environmental loads, as it has been demonstrated also with the wind tunnel test [2]. In addition, it has a favourable configuration towards the safety purposes: in case of an evacuation for an accident in one of the tubes, the people can be evacuated in the other tunnel. This implies the need of connecting the tubes with different elements at several levels: both road and pedestrian.

In addition to this main connection elements, a cross bracing system is giving to the structure the necessary rigidity towards the horizontal loads. The horizontal alignment of the bridge is helping for this purpose and in general the geometry of the structure has been chosen during the design in order to tune the behaviour of the structure out from the dangerous resonance area of the environmental loads. 


\section{Influence of the materials}

In this regard, also the material can play a key role. Looking away from other characteristics of different materials, one can utilize the different densities to achieve favourable dynamic behaviour of a designed structure under defined environmental conditions. Here we use a simple example of Bjørnefjord SFTB to illustrate this.

Consider the wave induced responses in tube of the pontoon stabilized SFTB under wind seas. Due to the lack of long term measurements in the Bjørnefjord, the uncertainty of the 100 years wind seas' wave height and spectrum peak period leads to the fact that one must carry out sensitivity check of these parameters for the robustness of the design. If we approximately consider that the wave induced motions are linear responses, we will see that the responses will be a linear function of the wave height, which is straightforward. However, for the wave period this is not as simple. This is due to the fact that the eigen modes of the super long SFTB structure is extremely complicated. The first mode period will be around 2 to 3 minutes depending on length and configuration of the structure. And from this period down, the highest modes can be less than 2 to 3 seconds.

A sensitivity numerical test of the axial force in tube of the pontoon stabilized SFTB for varying wind sea spectral peak period (Tp) is shown here in Figure 6. By observing the force spectral density graph, one would see that the spectral density has greatly increased from $\mathrm{Tp}=4 \mathrm{~s}$ (green line) to that of the $T p=5 \mathrm{~s}$ (red line). Note that the increase happens manly between $0.1 \mathrm{~Hz}$ to 0.25 $\mathrm{Hz}$, which correspond to wave periods of 4 second to 10 second that contains the peak periods of both wave spectrum. By combining with the studied spectrum, this means that due to the $25 \%$ increase in $T \mathrm{p}$, the axial force increases significantly for the tubes for the given peak periods.

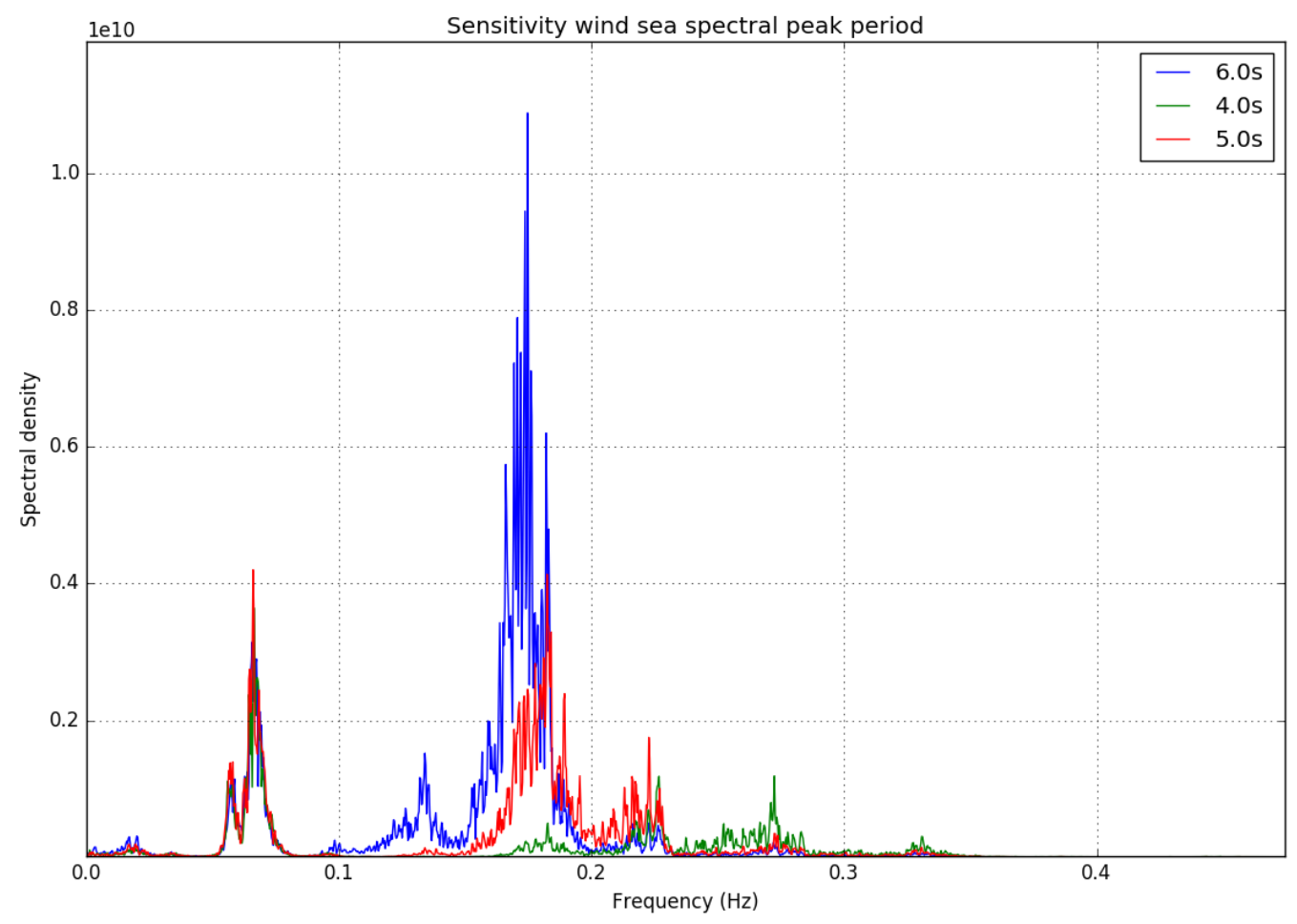

Figure 6 - Axial force in tube of the pontoon stabilized SFTB for varying wind sea spectral peak period (Tp). Note that the axial force increases significantly for $25 \%$ increase in Tp(from 4 second to 5 second) 
For the purpose of demonstration, we will not go further into the details of the significant increase of the axial forces. Of course, from the study it is shown that the responses of the bridge will be reduced either by reducing the wave periods or by reducing the modal periods of the modes that are around the wave periods in question. One will see that the first option is not realistic since no one can change the environmental conditions like the wave periods and so on. Thus, the only solution is to tune the structure properties. Here our aim is to reduce the eigen periods of the relevant modes around the wave periods. Based on simple structural dynamics one will see that the eigen periods are proportional to the square root of the modal masses of the structure.

To show how the eigen periods can be tuned via mass, we consider a simple example of a beam deeply submerged in the water. The bending eigen modes in y- (or z-) directions of a simply supported (pin-pin) beam under zero axial force can be calculated by the following equation, Nielsen (2004) [3]:

$$
\omega_{n, 0}=n^{2} \pi^{2} \sqrt{\frac{E I_{y / z}}{m l^{4}}}
$$

Here $n$ is the mode number, and unit length mass $m$ includes also added mass at the eigen period, which means an iterative process should be carried out in the calculation. If we keep the shape of the tubes, and all the other properties except the density as constant, the modal mass can be written as $m=\left(m_{a}+m_{s}\right)$. Here $m_{a}$ is added mass and $m_{s}$ is structure mass. Since the shape of the tubes are not changing, the added mass $m_{a}$ is constant too.

Now we define the volume of the beam is $V$ and $\boldsymbol{\rho}_{s}, \boldsymbol{\rho}_{\text {water }}$ the densities of structure material and water respectively. Then $m_{s}=\boldsymbol{\rho}_{s} V$ and $m_{a}=c \boldsymbol{\rho}_{\text {water }} V$. Here $m_{a}$ is constant if the tubes are deeply submerged and $\mathrm{c}$ is a constant called added mass coefficient. Then the modal mass can be expressed as $m=\left(m_{a}+m_{s}\right)=\left(\boldsymbol{\rho}_{s}+c \boldsymbol{\rho}_{\text {water }}\right) V$. From the above given equation (1) one will see that the corresponding modal periods are proportional to $\sqrt{\boldsymbol{\rho}_{s}+c \boldsymbol{\rho}_{\text {water }}}$. Usually the added mass coefficient is around 1, thus concrete density is dominant here. For example, we apply that the water density as $1000 \mathrm{~kg} / \mathrm{m}^{3}$ and common concrete density $2400 \mathrm{~kg} / \mathrm{m}^{3}$. If we use a different material, e.g., light weighted concrete or higher density concrete, the tuned eigen period/original period varies as shown in Figure 7 . One can see that by reducing the density by $50 \%$ the eigen period will be reduced $20 \%$ in this case. Combining with the earlier demonstrated results of sensitivity on wave periods' significant impact on the axial force, this exercise shows the potential of tuning structural responses by material density. 


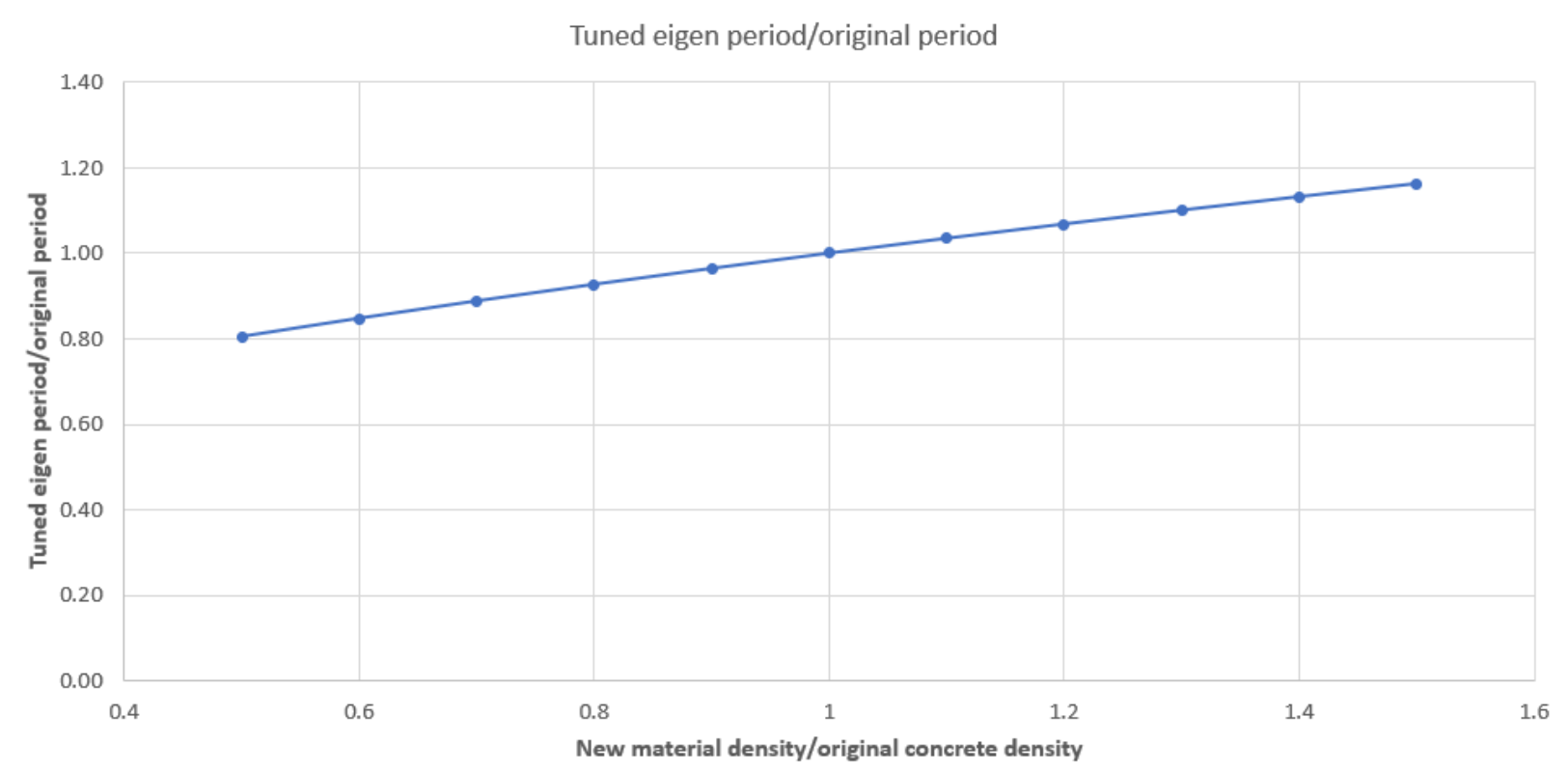

Figure 7 - The effect of using different density material on the eigen period of a structure

\section{3}

\section{The choice for the $\mathbf{E 3 9}$}

The requirements for the road, in terms of space and number of lanes, practically define the geometry of the structure and the consequent Archimede's lifting force. Among the available materials, concrete has been seen as a preferred solution, due to the possibility to use the structural material also as a permanet ballast. This wouldn't be possible with steel. Steel tubes have been chosen for the areas of the bridge near the shores, in the study done for the Bjørnafjord crossing. This was due to the higher stresses into the cross section. Nevertheless, the structure requires also some material to ballast the bridge and balance the huge lifting force due to the submergence. Light weight aggregate concrete $\left(17,5 \mathrm{kN} / \mathrm{m}^{3}\right)$ was chosen for those areas. Obviously, a specific protection with sacrificial anodes must be provided for steel elements. Concrete generally allows to reduce the maintenance of the structure and this implies a lower energy consumption and a better behaviour in terms of LCA considerations.

For the solution with floating pontoons, concrete pontoons have been chosen for the design for the Norwegian fjords. This was due mainly for the durability requirement and the consequent high cost for steel pontoons. The tethers, that are the same elements used for the TLP in Norway, are pre-stressed steel elements of a diameter of approximatively 1 meter and a thickness of 40 millimetres. They can reach a length of several hundred meters.

\subsection{Further applications}

Concrete represents a viable solution for the SFTB, especially in terms of durability and lower maintenance. Due to the complex behaviour of the structure towards the environmental loads, the possibility to tune the structure is crucial for designing a robust solution. In this regard, the possibility of acting on the density of the material has demonstrated a great potential for the design. 


\section{CONCLUSIONS}

Concrete has played and is playing a significant role in the studies for the crossings along E39. The choice of the material has been seen to be of a huge influence on various aspect of the design: from the cost, to the response towards special loads, to the behaviour of the structure under the environmental loads. It is worth to mention that concrete allows to minimize the maintenance for the life-service of the structure, especially for the part of the bridges in the splash-zone in an aggressive environment. This implies not only choosing a material that consumes less energy in the production phase [4],[2] but, thanks to the minimum maintenance, having the possibility to reduce the whole impact of the structure in terms of emissions and energy consumption.

The influence of the mass and the damping on the dynamic behaviour of these structures bring the material choice into the key parameters for a successful design and opens the project to further and optimized possibilities. The technological development of production, construction and characteristics, and the knowledge and experience in the industry, is very important for the further choice of materials for the E39 project. This development of common practice in the industry may be crucial for the feasibility of further projects.

\section{REFERENCES}

1. Xiang X, Minoretti A, Eidem M E, Belsvik K H, Aasland T E, \& Vodolazkin M: "Simplified hydrodynamic design procedure of a submerged floating tube bridge across the Digernessund of Norway". Proceedings, ASME 2017, 36th International Conference on Ocean, Offshore and Arctic Engineering. American Society of Mechanical Engineers Digital Collection, June 2017.

2. Hoffmann K, Rasmussen J T, Hansen S O, Reiso M, Isaksen B \& Aasland T E: "The use of wind tunnel facilities to estimate hydrodynamic data". Proceedings, Experimental Fluid Mechanics, Prague, Czech Republic, 2015

3. Nielsen S R K: "Vibration Theory", Vol. 1. Linear Vibration Theory. Aalborg tekniske Universitetsforlag, Aalborg, Denmark.

4. Hammervold J, Reenaas M \& Brattebø H: "Environmental Life Cycle Assessment of Bridges”. DOI: 10.1061/(ASCE)BE.1943-5592.0000328. C 2013. American Society of Civil Engineers. 